\title{
Circuito insulinérgico cerebral. De las bases a su impacto en la clínica
}

\author{
Brain insulin circuit. From the basics to impact on the clinic
}

Martín de J. Sánchez-Zúñiga ${ }^{*}$, Raúl Carrillo-Esper², Herlinda Sánchez-Pérez', Antonio González-Chávez ${ }^{3}$ y Sandra Elizondo-Argueta ${ }^{4}$

${ }^{1}$ Unidad de Terapia Intensiva, Instituto Nacional de Rehabilitación Luis Guillermo Ibarra Ibarra; ${ }^{2}$ División de Áreas Críticas, Instituto Nacional de Rehabilitación Luis Guillermo Ibarra Ibarra; ${ }^{3}$ Asociación Mexicana para el Estudio Multidisciplinario del Síndrome Metabólico, A.C., Hospital General de México Dr. Eduardo Liceaga; ${ }^{4}$ Unidad de Proyectos Especiales, Asociación Mexicana para el Estudio Multidisciplinario del Síndrome Metabólico, A.C., Instituto Mexicano del Seguro Social. Ciudad de México, México

\begin{abstract}
Resumen
El descubrimiento y la síntesis de la insulina ha sido vitales en el estudio y el tratamiento de la diabetes mellitus. Desde los estudios realizados por el Dr. Nicolae C. Paulescu en 1921 y sus descripciones de la pancreína, antes de los publicados por Banting y Macleod, galardonados con el Premio Nobel en 1923, se han descubierto cada vez más acciones metabólicas y no metabólicas fundamentales para la vida, el crecimiento y el desarrollo de diferentes órganos y sistemas. En la actualidad, el estudio de esta hormona se nutre con más evidencia científica de su utilidad en blancos terapéuticos no metabólicos. Diversos estudios en modelos animales han demostrado su participación en el desarrollo del sistema nervioso central, la regeneración, la apoptosis neuronal y la transmisión sináptica, así como los efectos de su disregulación en la fisiopatología de enfermedades como la demencia. En la actualidad, diferentes investigadores han demostrado la síntesis de insulina en el cerebro, los mecanismos por los cuales atraviesa la barrera hematoencefálica y cómo regula sistemas no metabólicos ligados con la nueromodulación. Este documento trata de integrar estos hallazgos en un sistema insulinérgico cerebral y su posible traducción en la práctica clínica.
\end{abstract}

Palabras Clave: Alzheimer. Cerebro. Demencia. Insulina.

\begin{abstract}
The discovery and synthesis of insulin has been vital in the study and treatment of diabetes mellitus. From the studies carried by Dr. Nicolae C. Paulescu in 1921 and descriptions of the pancrein, before those published by Banting and Macleod, the Nobel Prize winners in 1923, more metabolic and non-metabolic actions have been discovered and that are fundamental for life, growth and development of different organs and systems. Diverse studies in animal models have shown the participation in the development of the central nervous system, regeneration, neuronal apoptosis, and synaptic transmission, as well as the effects of its dysregulation in the pathophysiology of diseases such as dementia. Different researchers have demonstrated the synthesis of insulin at the brain, the mechanisms through which the blood-brain barrier crosses and how it regulates non-metabolic systems linked with the nueromodulation. This document to integrate these findings in the cerebral insulin circuit and the translation in clinical practice.
\end{abstract}

Key Words: Alzheimer's. Brain. Dementia. Insulin.

\section{Correspondencia:}

*Martín de J. Sánchez-Zúñiga

Avda. México Xochimilco, 289

Col. Arenal de Guadalupe, Del. Tlalpan

Fecha de recepción: 03-07-2018

C.P. 14389, Ciudad de México, México

E-mail: mjsanchez@inr.gob.mx

DOI: $10.24875 / C I R U .18000572$
Cir Cir. 2020;88(1):100-106

Contents available at PubMed www.cirugiaycirujanos.com (http://creativecommons.org/licenses/by-nc-nd/4.0/). 
«No se puede entender la evolución de la vida sin la insulina.»

Martín de Jesús Sánchez Zúñiga, 2018

\section{Introducción}

Durante muchos años prevaleció el concepto de que la insulina no atravesaba la barrera hematoencefálica, ni se sintetizaba en el tejido cerebral. Los primeros reportes de Margolis y Altzuler demostraron en modelos murinos y caninos la existencia de insulina en el líquido cefalorraquídeo, no obstante sin encontrar en ese momento una constante lineal ni alguna correlación con los niveles de insulina plasmática. Investigaciones posteriores de Banks y colaboradores, demostraron un mecanismo saturable de transporté de insulina que permite el cruce de la barrera hematoencefálica y que es independiente de los niveles de glucosa plasmática (la mayoría de la insulina cruza la barrera hematoencefálica en condiciones de normoglucemia) $)^{1-4}$. Investigaciones posteriores han permitido demostrar que la insulina no solo cruza la barrera hematoencefálica, sino que también es sintetizada en regiones específicas de grupos neuronales y que además cumple con funciones de señalización no metabólica.

Este documento recopila de manera puntual la evidencia científica y propone la existencia de un circuito insulinérgico cerebral, que es fundamental para el desarrollo del sistema nervioso central, y que sus alteraciones pueden ser parte importante de la fisiopatología de enfermedades como la de Alzheimer ${ }^{5-7}$.

\section{Insulina cerebral}

Los estudios de Dorn, et al. ${ }^{8}$ demostraron la presencia de péptido $C$ y proinsulina en diferentes zonas del cerebro, concentrándose principalmente en el hipotálamo. Los estudios de Zhao, et al. ${ }^{9}$, marcando el RNA mensajero de proinsulina 1, han mostrado que el predominio de la expresión se encuentra en el hipocampo, el bulbo olfatorio, el córtex piriforme y las células de Purkinje del córtex cerebral. Otros estudios han demostrado que solo un subgrupo de neuronas son las encargadas de la síntesis de insulina, principalmente en el hipocampo $0^{10-13}$.

El receptor de insulina $(\mathrm{RI})$ no tiene una distribución uniforme en todo el cerebro. Las primeras investigaciones de la presencia del RI en el tejido cerebral hechas con radiomarcadores en diferentes modelos animales mostraron que la concentración del RI está limitada solo a algunos sitios especiales, como las regiones circunventriculares, el hipotálamo medial, las regiones paravagales mediales, el plexo coroideo y algunas regiones del sistema nervioso periférico ${ }^{14}$.

Estudios posteriores con RNA mensajero del RI mostraron que las zonas con mayor densidad se distribuyen en regiones del hipotálamo, el cerebelo, las células granulares del bulbo olfatorio, el giro dentado, las células piramidales, el córtex piriforme, el hipocampo, el plexo coroideo y el núcleo arcuato del hipotálamo. Una de las características principales de la distribución del $\mathrm{RI}$ es que no está relacionado directamente con la densidad celular ni con la mayor cantidad de flujo sanguíneo, pero sí es abundante en las regiones con alta densidad de dendritas y sinapsis, por lo que es posible que esta relación tenga un importante papel en la actividad neuronal, fenómeno que es apoyado por los hallazgos del alto contenido de las fracciones IRSp58 e IRSp53 del sustrato del receptor de insulina (SRI), así como otros sustratos similares a efectores tipo fosfatidilinositol 3 cinasa en las sinapsis del cerebelo, el córtex cerebral y las neuronas del hipocampo ${ }^{15-21}$.

El RI es una proteína de la familia de los receptores de cinasas, y aunque ambos RI (cerebral y periférico) se comportan con la misma farmacología y cinética, existen diferencias en tamaño molecular, antigenicidad y composición de hidratos de carbono, así como en la regulación mediada por la insulina. Una de las principales diferencias es el tipo de respuesta a la cantidad de insulina: mientras que el receptor periférico responde con regulación a la baja (con internalización y degradación), el receptor cerebral se mantiene constante.

El desarrollo embrionario del RI y su distribución en sitios específicos del cerebro también están relacionados con los efectos de crecimiento, modulación y desarrollo cerebral. Los hallazgos han mostrado que la densidad del RI en la etapa fetal es diferente a la de la etapa adulta. En estudios post mortem de fetos humanos, y principalmente en modelos múridos, se ha visto que la densidad del RI disminuye con la edad, aunque al parecer esto se limita al bulbo olfatorio; además, se han encontrado modificaciones en el tamaño molecular de las subunidades alfa ${ }^{22-29}$.

La insulina y otras moléculas, como el factor de crecimiento similar a la insulina tipo 1, desempeñan un papel importante en la señalización y el metabolismo energético de las neuronas y de las células gliales. La activación del RI media procesos moleculares, la vía de las MAP cinasas (proteasas activadas por mitógeno, MAPK en inglés) y la vía del PI3k, que 
INSULINA CEREBRAL

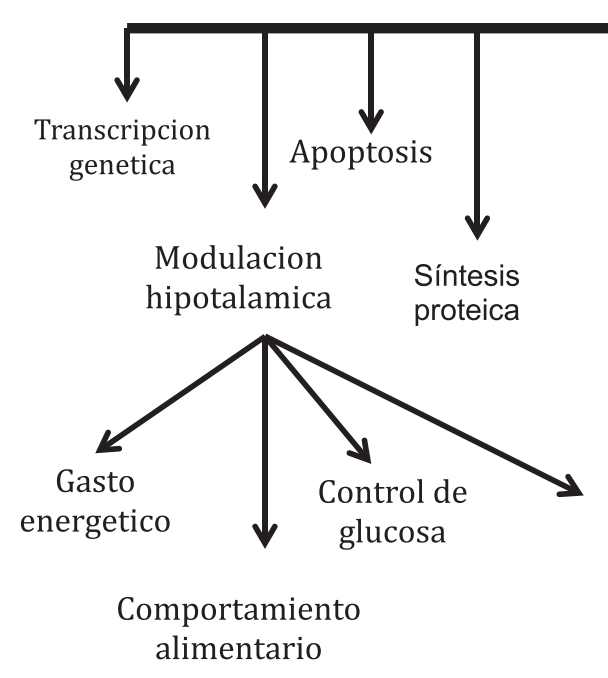

Figura 1. Acciones de la insulina en el cerebro.

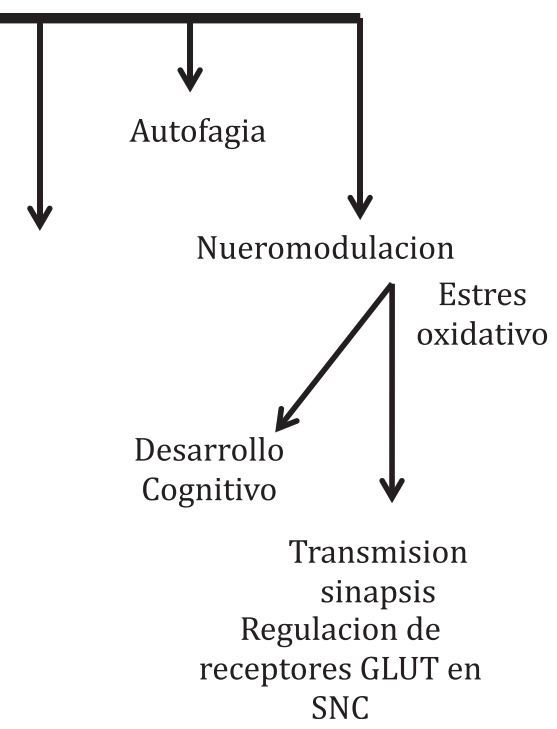

entre otras acciones inhiben la apoptosis y fomentan el crecimiento, la supervivencia celular, la expresión genética, el ensamblaje del citoesqueleto, la formación de sinapsis, la transmisión nerviosa y la plasticidad neuronal. La vía de MAPK cumple funciones principalmente de señalización y activación de mecanismos de transcripción genética, favoreciendo el crecimiento y la reparación neuronal. La modulación de la vía de PI3k participa, en las neuronas, regulando la fosforilación/desfosforilación de la proteína tau, mecanismo que es dependiente de la regulación de la actividad de la isoforma beta de la cinasa de glucógeno sintasa (GSK3-b en inglés) ${ }^{30-33}$ (Fig. 1).

Tanto las acciones metabólicas como las no metabólicas de la interacción de la insulina cerebral con su receptor son parte fundamental en la regulación de los efectos energéticos derivados de la absorción y el metabolismo de la glucosa en las células neuronales y gliales. Estos mecanismos dependen principalmente de la regulación de la insulina sobre sus transportadores GLUTS (transportadores de difusión facilitada por hexosas), de los cuales los GLUTS 1 y 3 son los más abundantes en el cerebelo, el hipocampo, el córtex, el hipotálamo, el bulbo olfatorio, el giro dentado, la amígdala y el córtex olfatorio primario, a diferencia de los GLUTS 4 y 8 , que se encuentran en menor cantidad y limitados a algunos grupos neuronales y células gliales, particularmente distribuidos en las regiones apicales y proximales de los cuerpos celulares ${ }^{34-38}$ (Tabla 1).

El GLUT-1 es el transportador de glucosa más ampliamente distribuido en el ser humano; tiene una alta expresión en tejidos fetales, como eritrocitos, células

endoteliales, células nerviosas, placenta, linfocitos, riñón, retina y tejido adiposo. Presenta una alta afinidad por la glucosa, por lo que es capaz de transportar de manera constante glucosa hacia el interior de la célula de manera independiente de la cantidad de insulina y de glucosa plasmática, y por ello es de suma importancia en el tejido cerebral, donde su expresión se mantiene de manera constante. Una de las características más importantes es que GLUT 1 puede ser transportador de otras moléculas, como galactosa, manosa y glucosamina. Existen dos isoformas de GLUT 1: la isoforma de $55 \mathrm{kDa}$ se distribuye principalmente en células endoteliales de la barrera hematoencefálica, la membrana neuronal y los eritrocitos, y la segunda isoforma, de menor peso molecular, es casi exclusiva de las células gliales. Las enfermedades derivadas de las alteraciones o de la deficiencia de GLUT 1 se manifiestan por graves alteraciones funcionales del sistema nervioso central, como el síndrome de deficiencia de GLUT 1, el cual se caracteriza por convulsiones, retraso en el desarrollo, trastorno complejo del movimiento y cambios electroencefalográficos en el ayuno. Los estudios de resonancia magnética de estos pacientes muestran una grave disminución en la captación de glucosa en la corteza cerebra|39-41.

El GLUT 3 también es un transportador de glucosa de alta afinidad, que fue descubierto principalmente en tejido cerebral. Su distribución se limita en tejido fetal y adulto al músculo miocárdico y esquelético, al hígado, la placenta y el tejido cerebral. Su principal característica es que es un coagregado del GLUT 1, ya que, al igual que este, tiene la función de transporte 
Tabla 1. Transportadores de glucosa en el cerebro

\begin{tabular}{lll}
\hline $\begin{array}{l}\text { Isoforma de } \\
\text { GLUTS }\end{array}$ & Localización & Grupo celular \\
\hline GLUT 1 & Ubicuo y abundante & Células gliales y endotelio \\
GLUT 2 & Limitado a hipotálamo & Neuronas, glía, tanicitos \\
GLUT 3 & Abundante en cerebelo, córtex, hipocampo y cuerpo estriado & Neuronas, glía y endotelio \\
GLUT 4 & $\begin{array}{l}\text { Solo en áreas especiales del bulbo olfatorio, hipocampo (giro } \\
\text { dentado), cerebelo e hipotálamo }\end{array}$ & Neuronas y glía \\
GLUT 8 & $\begin{array}{l}\text { Limitado a hipotálamo, cerebelo, giro dentado, amígdala y } \\
\text { córtex olfatorio primario }\end{array}$ & Neuronas: dendritas proximales \\
\hline
\end{tabular}

GLUTS: transportadores de glucosa.

constante de glucosa de manera independiente de las concentraciones plasmáticas de glucosa y de insulina. Se ha demostrado que la alteraciones en la expresión de este transportador o las mutaciones en su gen (SLC2A3, localizado en el cromosoma 12) se asocian con alteraciones metabólicas graves en la etapa neonatal, retraso psicomotriz y restricción en el crecimiento intrauterino. Otros estudios han demostrado mutaciones en células tumorales y su mayor capacidad metastásica, como en líneas celulares de tumores testiculares. Las alteraciones del gen de este transportador (mayor cantidad de copias) también se asocian con la aparición más temprana de los síntomas de la enfermedad de Huntington ${ }^{42-46}$.

El GLUT 8 comparte con el GLUT 3 la alta afinidad por la glucosa. Se ha encontrado de manera predominante en células testiculares, blastocitos, cerebelo e hipocampo, y en menor cantidad en bazo, próstata, hígado, corazón y musculo esquelético. La capacidad de transporte de la glucosa también es independiente de la cantidad de glucosa plasmática y es regulada directamente por el estímulo insulinérgico. Por el momento se ha demostrado sobreexpresión del gen que lo codifica (SLC2A8) en la enfermedad de Alzheimer ${ }^{47,48}$.

\section{Propuesta del circuito insulinérgico cerebral}

De acuerdo con la descripción de la evidencia científica, puede establecerse, al menos de manera teórica, la existencia de un circuito insulinérgico cerebral. Este puede describirse, según su cinética, con los siguientes puntos importantes (Fig. 2):

- La insulina plasmática atraviesa la barrera hematoencefálica a través de un sistema saturable de poros entre las células endoteliales (espacios de Virchow-Robin) y los plexos coroideos (modelo tradicional de efecto paracrino).
- La insulina también es sintetizada en grupos celulares de zonas específicas del cerebro, el córtex frontal, el bulbo olfatorio, el cerebelo, el hipocampo y las células de Purkinje, e interactúa con su receptor a través de una vía autocrina (modelo no tradicional de efecto autocrino).

- La insulina cerebral, de cualquiera de sus orígenes, interactúa con su receptor, el cual tiene una densidad de distribución en sitios específicos del cerebro, como las regiones circunventriculares, el hipotálamo medial, las regiones paravagales mediales, el plexo coroideo, el bulbo olfatorio, el giro dentado, las células piramidales, el núcleo arcuato del hipotálamo y algunas regiones del sistema nervioso periférico.

- La acción de la insulina con su receptor, a través de la fosforilación de residuos de tirosina, desencadena señalizaciones principalmente en dos vías: la vía de MAPK, que se encarga principalmente de señalización, traducción y señalización genética, y la vía de la PKB/Akt (phosphoinositide-3-kinase-protein kinase B/Akt), que se encarga de las acciones metabólicas y de señalización secundaria no metabólicas.

- La fosforilación y la activación de la vía de PKB/ Akt se encarga de la regulación y el control de cinasas como la GSK3, que dentro de sus actividades secundarias regula la fosforilación/desfosforilación de la proteína tau ${ }^{49}$.

- La señalización y regulación mediada por PKB/ Akt también regula la actividad de AS160 (sustrato de Akt de $160 \mathrm{kDa}$ ) y Rab (GTPasa monomérica de la subfamilia Rab de proteínas relacionadas con Ras), encargados de la activación y la translocación de transportadores de glucosa (GLUTS 1, 3, 4 y 8) que se encuentran distribuidos en sitios específicos del cerebro. 


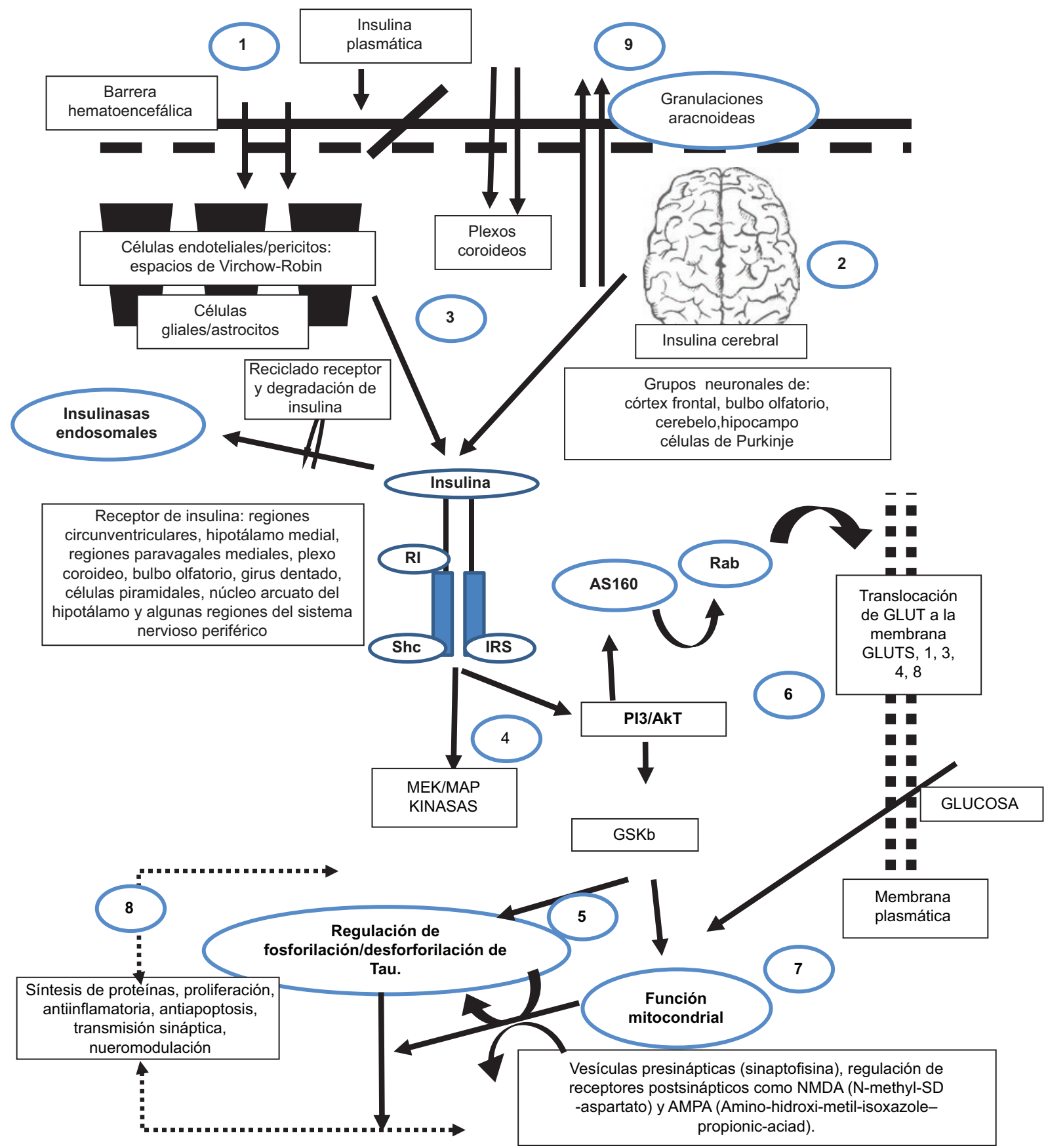

Figura 2. Circuito insulinérgico cerebral (véase el texto para explicación). AMPA: amino-hidroxi-metil-isoxazol-ácido-propiónico; GLUT: transportadores de glucosa; GSKb: cinasa de glucógeno 3b; MEK/MAP: complejo de proteínas cinasas activadas por mitógeno; NMDA: N-metil-Daspartato; PI3/AKT: complejo fosfatidilinositol 3 cinasa; RI: receptor de insulina; Shc: proteína transductora tipo 1; SRI: sustrato del receptor de insulina.

- La alta sensibilidad de los GLUTS específicos, como el 1 y el 3 , permiten la entrada constante de glucosa al cerebro (independientemente de las concentraciones plasmáticas de glucosa y de insulina), lo que mantiene una constante fuente energética para la función mitocondrial, antiinflamatoria, antiapoptosis, neuromodulación, crecimiento, proliferación, señalización sináptica, estrés oxidativo, etcétera.
- Las insulinasas endosomales se encargan de la degradación de la insulina. El RI es reciclado para su nueva translocación a la membrana plasmática. En condiciones de resistencia a la insulina, con sistema saturable e hiperinsulinemia (diabetes tipo 2 y síndrome metabólico), el RI es transportado a los lisosomas para su degradación, regulando a la baja su disponibilidad, 
mecanismo que desempeña un papel importante en la resistencia a la acción de la insulina ${ }^{50}$.

\section{Integración fisiopatológica}

El término de diabetes mellitus tipo 3, acuñado recientemente por varios investigadores, podría ser explicado por el mecanismo de desregulación de la señalización mediada por la insulina en este circuito insulinérgico cerebral, que se traduce en la hiperfosforilación de proteínas esenciales en la neurotransmisión sináptica, que se manifiestan clínicamente como deterioro cognitivo.

De acuerdo con los hallazgos histopatológicos en modelos animales, cerebros humanos in vivo y cerebros post mortem, existen indicios que apoyan que las alteraciones en la señalización de la insulina en el cerebro participan en la aparición de los principales fenómenos patológicos observados en la enfermedad de Alzheimer, como el depósito de beta-amiloide (BA), la hiperfosforilación de la proteína tau, la inflamación y el aumento de biomarcadores plasmáticos y de líquido cefalorraquídeo. La resistencia a la insulina es parte fundamental de estos mecanismos, ya sea por la misma regulación a la baja de los $\mathrm{RI}$ o por la sobresaturación de las enzimas degradadoras de insulina (insulinasas), que comparten un mecanismo de acción secundario en la eliminación de los péptidos BA que son generados por la acción de las secretasas específicas que degradan a estos péptidos.

El bloqueo del RI facilita la fosforilación de residuos de serina de los sitios de unión SRI-1-4 (normalmente de fosforilación de residuos de tirosina). Este desequilibrio bloquea la señalización de las dos principales vías de respuesta a la acción de insulina. Por un lado, la que es mediada por MAPK, que entre otras acciones regula la actividad de otras cinasas, proteínas y proteinasas que se encargan de la regulación y la eliminación de productos tóxicos, incluyendo la depuración de los péptidos de BA. Por otro lado, al evitar la activación de la PI3k, se pierde la regulación negativa de cinasas como GSK3b y las cinasa tau-tubulina (TauK) y KDc2 y 5 (cinasas similares a las ciclinas 2 y 5 ), que normalmente controlan la fosforilación de la proteína tau.

Este desequilibrio en la regulación de la fosforilación/ desfosforilación facilita la agregación de tau en racimos u ovillos neurofibrilares (formados por proteína tau hiperfosforilada), alterando la estructura microtubular y bloqueando la transmisión axonal y sináptica, lo que limita la disponibilidad de neurotransmisores, de vesículas presinápticas como sinaptofisina, acúmulo de BA y regulación a la baja de los receptores postsinápticos como NMDA (N-metil-D-aspartato) y AMPA (amino-hidroxi-metil-isoxazol-ácido propiónico). Además, el bloqueo de la señalización de insulina limita la expresión de los transportadores transmembrana de glucosa (GLUT), que limitan la entrada de glucosa para el metabolismo y la función energética mitocondrial que genera mayor estrés oxidativo, inflamación y apoptosis ${ }^{51-57}$.

\section{Conclusiones}

Hasta el momento existe evidencia científica que demuestra que la insulina desempeña un papel preponderante en la neuromodulación, y no solo desde la embriogénesis fomentando el crecimiento y el desarrollo del sistema nervioso central, sino también como un importante neuromodulador de respuestas no metabólicas en la etapa adulta, principalmente asociadas con la transmisión sináptica, la apoptosis cerebral, la regeneración neuronal, la inflamación, el estrés oxidativo, etcétera. También existe cada vez más evidencia de que esta hormona puede ser sintetizada en grupos específicos de células neuronales, así como de la capacidad de atravesar la barrera hematoencefálica, y de que al interactuar con su receptor, el cual se encuentra distribuido solo en algunas zonas especiales del cerebro, modula una serie de respuestas no metabólicas que están involucradas en el funcionamiento adecuado de la transmisión sináptica. Probablemente el más claro ejemplo de esta disfunción sea la desregulación de la vía de fosforilación/desfosforilación de la proteína tau y la formación de ovillos neurofibrilares, como uno de los principales hallazgos fisiopatológicos de la enfermedad de Alzheimer ${ }^{58-61}$.

\section{Conflicto de intereses}

Los autores declaran que no existe conflicto de intereses.

\section{Responsabilidades éticas}

Protección de personas y animales. Los autores declaran que para esta investigación no se han realizado experimentos en seres humanos ni en animales.

Confidencialidad de los datos. Los autores declaran que han seguido los protocolos de su centro de trabajo sobre la publicación de datos de pacientes.

Derecho a la privacidad y consentimiento informado. Los autores declaran que en este artículo no aparecen datos de pacientes. 


\section{Bibliografía}

1. Banks WA. The source of cerebral insulin. Eur J Pharmacol. 2004;490:5-12

2. Margolis RU, Altszuler N. Insulin in the cerebrospinal fluid. Nature 1967;215:1375-6.

3. Woods SC, Porte D. Relationship between plasma and cerebrospinal fluid insulin levels of dogs. Am J Physiol Gastrointest Liver Physiol. 1977;233:G331-4

4. Banks WA, Jaspan JB, Huang W, Kastin AJ. Transport of insulin across the blood-brain barrier: saturability at euglycemic doses of insulin. Peptides. 1997; 18:1423-9.

5. Banks WA, Owen JB, Erickson M. Insulin in the brain: there and back again. Pharmacol Ther. 2012;136:82-93.

6. Guo T, Noble W, Hanger DP. Roles of tau protein in health and disease. Acta Neuropathol. 2017;133:665-704.

7. Gashemi R, Haeri A, Dargahi L, Mohamed Z, Ahmandiani A. Insulin in the brain: sources, localization and functions. Mol Neurobiol. 2013;47:145-71.

8. Dorn A, Rinne A, Bernstein H, Hahn Ziegler M. Insulin and C-peptide in human brain neusons (insulin peptide/brain peptides/inmmunohistochemistry/radioinmmunoassay). J Hirnsforsch. 1978;24;495-9.

9. Zaho W, Chen H, Xu H, Moore E, Meiri N, Quon MJ, et al. Brain insulin receptors and spatial memory. Correlated changes in gene expression, tyrosine phosphorylation, and signaling, molecules in the hippocampus of water maze trained rats. J Biol Chem. 1999;274:34893-902.

10. Singh BS. Insulin gene expression in immortalized rat hippocampal and pheochromocytoma-12 cell lines. Regul Pept. 1997:69:7-14.

11. Clarke DW, Mudd L, Boyd FT Jr, Fields M, Raizada MK. Insulin is released from rat brain neuronal cells in culture. J Neurochem. 1986;47:831-6.

12. Raizada MK. Localization of insulin-like immunoreactivity in the neurons from primary cultures of rat brain. Exp Cell Res. 1983;143:351-7.

13. Abraham MA, Filippi BM, Kamg GM, Kim MS, Lam TK. Insulin action in the hypothalamus and dorsal vagal complex. Exp Physiol. 2014;99:1104-9.

14. Ziegler AN, Levinson SW, Wood TL. Insulin and IGF receptor signaling in neual-stem-cell homeostasis. Nat Rev Endocrinol. 2015;3:161-70.

15. Waldbillig RJ, LeRoith D. Insulin receptors in the peripheral nervous system: a structural and functional analysis. Brain Res. 1987;409:215-20.

16. Mielke J, Wang Y. Insulin, synaptic function, and opportunities for neuroprotection. Prog Mol Biol Transl Sci. 2011;98:133-86.

17. Hill J, Lesniak M, Pert C, Roth J. Autoradiographic localization of insulin receptors in rat brain: prominence in olfactory and limbic areas. Neuroscience. 1986;17:1127-38.

18. Schulingkamp R, Pagano T, Hung D, Raffa R. Insulin receptors and insulin action in the brain: review and clinical implications. Neurosci Biobehav Rev. 2000;24:855-72.

19. Kleinridder A, Ferris HA, Cai W, Khan R. Insulin action in brain regulates systemic metabolism and brain function. Diabetes. 2014:63:2232-43.

20. Banks W. Role of the blood-brain barrier in the evolution of feeding and cognition. Ann NY Acad Sci. 2012;1264:13-9.

21. Tiendemann LJ, Schmid SM, Hettel J, Giesen K, Francke CB, Brassen S. Central insulin modulates food valuation via mesolimbic pathways. $\mathrm{Na}$ ture Communications. 2017;8: 16052

22. Heidenreich KA, Zahniser NR, Berhanu P, Brandenburg D, Olefsky JM. Structural differences between insulin receptors in the brain and peripheral target tissues. J Biol Chem. 1983;258:8527-30.

23. Yip CC, Moule ML, Yeung CWT. Characterization of insulin receptor subunits in brain and other tissues by photoaffinity labeling. Biochem Biophys Res Commun. 1980;96:1671-8.

24. LeRoith D, Lowe WL Jr, Shemer J, Raizada MK, Ota A. Development of brain insulin receptors. Int J Biochem. 1988;20:225-30.

25. Gralle M. The neural insulin receptor in its environment. J Neurochem 2017:140:359-67.

26. Tchilian E, Zhelezarov I, Petkov V, Hadjiivanova Cl. Insulin binding is decreased in olfactory bulbs of aged rats. Neuropeptides. 1990:17:193-6.

27. Potau N, Escofet M, Martínez M. Ontogenesis of insulin receptors in human cerebral cortex. J Endocrinol Investig. 1991;14:53-8.

28. Zaia A, Piantanelli L. Insulin receptors in the brain cortex of aging mice. Mech Ageing Dev. 2000;113:227-32.

29. Werther GA, Hogg A, Oldfield BJ, McKinley MJ, Figdor R, Allen AM, et al. Localization and characterization of insulin receptor in rat brain and pituitary gland using in vitro autoradiography and computerized densitometry. Endocrinol. 1987:121:1562-70.

30. Steen E, Terry BM, Rivera EJ, Cannon JL, Neely TR, Tavares R, et al. Impaired insulin and insulin-like growth factor expression and signaling mechanisms in Alzheimer's disease - is this type 3 diabetes? J Alzheimers Dis. 2005;7:63-80.

31. Van der Heude LP, Remarkers GM, Smidt MP. Insulin signaling in the central nervous system: learning to survive. Prog Neurobiol. 2006;79:205-21.

32. Jagua A, Marín RA, Granados LA, Ávila V. Insulina cerebral. Colomb Med. 2008;39:107-16
33. Liu Y, Liu F, Grundke-lqbal I, Iqbal K, Gong CX. Deficient brain insulin signalling pathway in Alzheimer's disease and diabetes. J Pathol. 2011;225:54-62.

34. Joost HG, Thorens B. The extended GLUT-family of sugar/polyol transport facilitators: nomenclature, sequence characteristics, and potential function of its novel members. Mol Membr Biol. 2001;18:247-56.

35. Barrett MP, Walmsley AR, Gould GW. Structure and function of facilitative sugar transporters. Curr Opin Cell Biol.1999;11:496-502.

36. Huang S, Czech MP. The GLUT 4 glucose transporter. Cell Metabol. 2007;5:237-52.

37. Mueckler M, Thorens B. The SLC2 (GLUT) family of membrane transporter. Mol Aspects Med. 2013;34:121-38.

38. Blázquez E, Velázquez E, Hurtado-Carneiro V, Ruiz-Albusac JM. Insulin in the brain: its pathophysiological implications for estates related with central insulin resistance, type 2 diabetes and Alzheimer's disease. Front Endocrinol. 2014;5:1-21.

39. Mueckler M, Caruso C, Baldwin SA, Panico M, Blech I, Morris HR. Sequence and structure of a human glucose transporter. Science. 1985:229:941-5.

40. Sandoval-Muñiz RJ, Vargas-Guerrero B, Flores-Alvarado LJ, Gurrola-Díaz CM. Glucotransportadores (GLUT): aspectos clínicos, moleculares y genéticos. Gac Med Mex. 2016;152:547-57.

41. Wang D, Kranz-Eble P, De Vivo DC. Mutation analysis of GLUT 1 (SLC2A1) in GLUT 1 deficiency syndrome. Human Mutat. 2000;16:224-31.

42. Mantych GJ, James DE, Chung HD, Debvaskar SU. Cellular localization and characterization of GLUT 3 glucose transporters isoform in human brain. Endocrinol. 1992;131:1270-8.

43. Janzen C, Lei MY, Cho J, Sullivan P, Shin BC, Devaskar SU. Placental glucose tranporters 3 (GLUT 3 ) is up-regulated in human pregnancies complicated by lated-onset intrauterine growth restriction. Placenta. 2013;16:1373-82.

44. Burant CF, Davison NO. GLUT 3 glucose transporter isoform in rat testis: localization, effect of diabetes mellitus, and comparation to human testis. Am J Pshysiol. 1994;267:R1488-95.

45. Howitt BE, Brooks JD, Jones S, Higgins JP. Identification and characterization of 2 testicular germ cell markers, GLUT 3, and cyclin A2. Appl Immunohistochem Mol Morphol. 2013;21:401-7.

46. Vitorri A, Breda $C$, Repici M, Orth M, Roos RA, Outeiro TF, et al. Copy-number variation of the neural glucose gene SLC2A3 and age of onset in Huntington's disease. Hum Mol Gent. 2014;23:3129-37.

47. Chong MS, Goh LK, Lim WS, Chan M, Tay L, Chen G, et al. Gene expression profiling of peripheral blood leukocytes shows consistent longitudinal downregulation of TOMM40 and upregulation of KIR2DI54, PLOD1, and SLC2A8 among fast progressors in early Alzheimer's disease. J Alzheimers Dis. 2013:34:399-405.

48. Ibberson M, Uldry M, Thorens B. GLUT XI, a novel mammalian glucose transporter expressed in the central nervous system and insulin-sensitive tissues. J Biol Chem. 2000;275:4607-12.

49. El Khoury NB, Gratuze M, Papon MA, Bretteville A, Planel E. Insulin dysfunction and tau pathology. Front Cell Neurosci. 2014;8:1-17.

50. Olivares RA, Arellano PA. Bases moleculares de la acción de la insulina. REB. 2008;27:9-18.

51. Querfurth HW, LaFerla FM. Alzheimer's disease. N Engl J Med. 2010;362:329-44.

52. Kumari M, Brunner E, Fuhrer R. Mini review: mechanisms by which the metabolic syndrome and diabetes impair memory. J Gerontol Biol Sci. 2000;55: B228-32

53. Gil-Bea FJ, Solas M, Solomon A, Mugueta C, Winblad B, Kivipelto M, et al. Insulin levels are decreced in the cerebral fluid of women with prodromal Alzheimer's disease. J Alzheimer's Dis. 2010;22:405-13.

54. Craft S, Peskind E, Schwartz MW, Schellenberg GD, Raskind M, Porte D Jr. Cerebrospinal fluid and plasma insulin levels en Alzheimer's disease: relationship to severity of dementia and apolipoprotein $\mathrm{E}$ genotype. Neurology. 1998;50:164-8

55. De la Monte SM. Type 3 diabetes is sporadic Alzheimer's disease: mini-review. Eur Neuropsychopharmacol. 2014:24:1954-60.

56. Dik MG, Jonker C, Comijs HC, Deeg DJ, Kok A, Yaffe K, et al. Contribution of metabolic syndrome components to cognition in older individuals. Diabetes Care. 2007:30:2655-60.

57. Morgan OO. Cyclin-dependent kinase: engines, clocks, and microprocessors. Annu Rev Cell. 1997;13:262-91.

58. Mandelkow EM, Biernat J, Drewes G, Gustke N, Trinezek B, Mandelkow E. Tau domains, phosphorylation, and interactions with microtubules. Neurobiol Aging. 1995;16:355-62.

59. Garcia T, Jay D. Fosforilación de tau y enfermedad de Alzheimer. Gac Med Mex. 2004:140:329-33.

60. Lovestone $\mathrm{S}$, Reynolds $\mathrm{CH}$. The phosphorylation of tau: a critical stage in neurodevelopment and neurodegenerative process. Neurosci. 1997;78:309-24

61. Sengupta A, Wu O, Grundke-lqbal I, Iqbal K, Singh TJ. Alzheimer-like phosphorylation of human tau by Cdk5. Moll Cell Biochem. 1997;167:99-105. 